Key messages

- Belief in Taian-Butsumetsu, a superstition relating to the six day lunar calendar, is common among Japanese people

- This study showed that the mean number of patients discharged on Taian (a lucky day) is the highest and that on Butsumetsu (an unlucky day) is the lowest

- Patients discharged on Taian were older, were more likely to be female, and had longer hospital stays than those discharged on other days

- The findings suggest that patients were extending their stay to leave hospital on Taian

- This superstitious belief increased the cost of medical care in Japan

extending hospital stay to the patients while taking into consideration the possible psychological impact of the superstition on health.

This study was presented at the 2nd Asian-Pacific congress of epidemiology, Tokyo, Japan, on 28 January 1998. We thank Mr Gert van Tonder of the Graduate School of Human and Environmental Studies at Kyoto University for his linguistic help and Mr Masahiro Natsume of Medical Informatics Department at Kyoto University (Kyoso Computer Co Ltd ES3 Implementation Department) for data collection.

Contributors: $\mathrm{KH}$ initiated the research, conducted analysis of the data and wrote the paper. TF participated in all processes and is guarantor for this paper. AE participated in data collection and discussion. MR and MM participated in the analysis of the data and discussion.

Funding: None

Competing interest: None declared.

1 Scott R, Scott H. Crocodile bites and traditional beliefs in Korogwe District, Tanzania. BMJ 1994;309:1691-2.

2 Scanlon TJ, Luben RN, Scanlon FL, Singleton N. Is Friday the 13th bad for your health? $B M J 1993 ; 307: 1584-6$.

3 Reiss RE, Ash AD. The eighth-month fetus: classical sources for a modern superstition. Obstet Gynecol 1988;71:270-3.

4 Blacher RS. Clusters of disaster: superstition and the physician. Gen Hosp Psychiatry 1983;5:279-84.

5 Kim YS. Fertility of the Korean populationin Japan influenced by a folk superstition in 1966. J Biosoc Sci 1979;11:457-64.

6 Kaku K. Were girl babies sacrificed to a folk superstition in 1966 in Japan? Ann Hum Biol 1975;2:391-3.

7 Kaku K. Increased induced abortion rate in 1966, an aspect of a Japanese folk superstition. Ann Hum Biol 1975;2:111-5.

8 Kaku K, Matsumoto YS. Influence of a folk superstition on fertility of Japanese in California and Hawaii, 1966. Am J Public Health 1975;65:170-4

9 Kaku K. Are physicians sympathetic to superstition? A study of Hinoe-Uma. Soc Biol 1972;19:60-4.

10 Uchida M. The calendar's tale for 12 months. Tokyo: Yuzankaku, 1991:10610.

11 Survey Department of Institute of Social Insurance. Drug tariff. Tokyo: Institute of Social Insurance, 1997.

12 Statistics and Information Department. Patient survey. Tokyo: Ministry of Health and Welfare, 1993:566.

13 Organisation for Economic Cooperation and Development. OECD health system facts and trends 1960-1991. Paris: OECD, 1993:215.

14 Oh VM. The placebo effect: can we use it better? BMJ 1994;309:69-70.

15 Dobrilla G, Scarpignato C. Placebo and placebo effect: their impact on the evaluation of drug response in patients. Dig Dis 1994;12:368-77.

16 Kleijnen J, de Craen AJ, van Everdingen J, Krol L. Placebo effect in double-blind clinical trials: a review of interactions with medications. Lancet 1994;344:1347-9.

17 Edward A, Walker JK, Wayne JK. Psychological factors affecting medical conditions and stress responses. In: Stoudemire A, ed. Human behavior. Philadelphia: Lippincott, 1990:64-83.

\title{
Life is sweet: candy consumption and longevity
}

\author{
I-Min Lee, Ralph S Paffenbarger Jr
}

Our attitude towards candy- -if it tastes that good, it can't be healthy"-betrays society's puritanical stance towards pleasure. Candy has been blamed for various ills, including hyperactivity in children; however, clinical trials have not supported this. ${ }^{1}$

Candy-sugar confectionery and chocolate-is not a recent invention: the ancient Arabs, Chinese, and Egyptians candied fruits and nuts in honey, and the Aztecs made a chocolate drink from the bean of the cacao tree. Today, Americans gratify themselves with, on average, $5.4 \mathrm{~kg}$ of sugar candy and $6.5 \mathrm{~kg}$ of chocolate per person annually. ${ }^{2}$

Since candy has existed for centuries, we surmised that it cannot be totally unhealthy. We decided to investigate whether candy consumption was associated with longevity.

\section{Subjects, methods, and results}

Subjects were from the Harvard alumni health study, an ongoing study of men entering Harvard University as undergraduates between 1916 and 1950. We included 7841 men, free of cardiovascular disease and cancer, who responded to a health survey in 1988 providing information on consumption of candy.
We asked about the average number of servings of candy eaten in the past year. Response options ranged from "almost never" to " $6+$ per day." In analyses, we regarded as non-consumers of candy the men who answered "almost never." The survey also asked about other health habits (see table). We obtained death

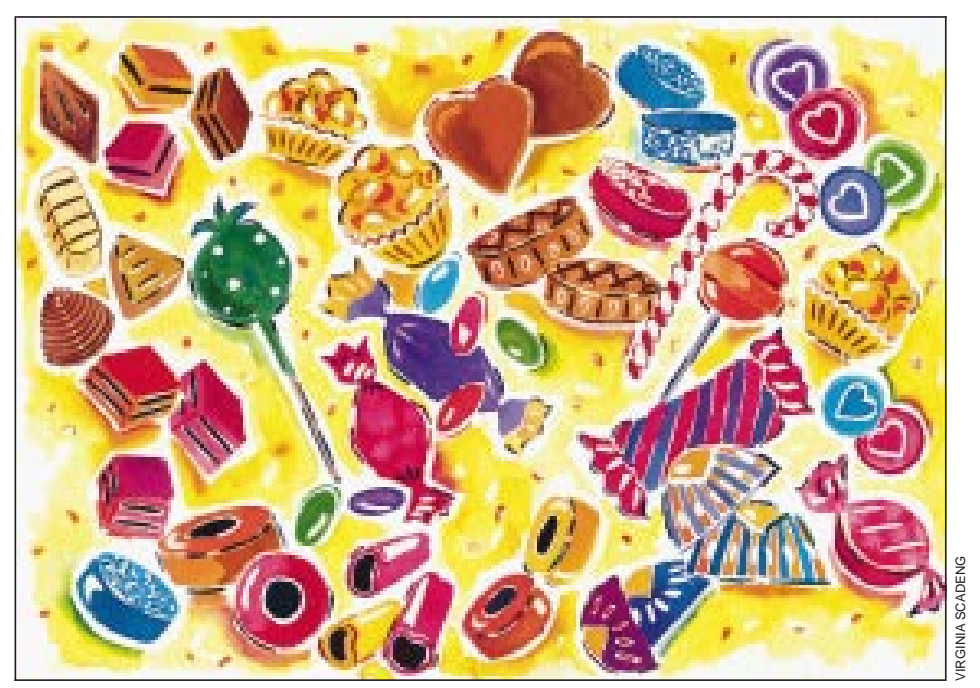


Comparison of non-consumers and consumers of candy. Values are medians (interquartile ranges) unless specified otherwise

\begin{tabular}{|c|c|c|c|}
\hline Attribute & $\begin{array}{c}\text { Non-consumers } \\
\text { of candy } \\
(\mathrm{n}=3312)\end{array}$ & $\begin{array}{l}\text { Consumers } \\
\text { of candy } \\
(\mathrm{n}=4529)\end{array}$ & $P$ value ${ }^{*}$ \\
\hline Age (years) & $65(60-72)$ & $65(60-71)$ & $<0.001$ \\
\hline Body mass index $\left(\mathrm{kg} / \mathrm{m}^{2}\right)$ & $24.39(22.69-26.22)$ & $24.41(22.95-26.44)$ & $<0.001$ \\
\hline Energy expenditure† (kcal/week) & $2018(952-3620)$ & $1926(868-3470)$ & 0.07 \\
\hline \multicolumn{4}{|l|}{ Cigarette habit: } \\
\hline No (\%) never smoked & $1201(36.4)$ & $1852(41.0)$ & \multirow{3}{*}{0.001} \\
\hline No (\%) past smoker & $1804(54.7)$ & $2333(51.7)$ & \\
\hline No (\%) current smoker & $296(9.0)$ & $331(7.3)$ & \\
\hline Duration of smoking, current smokers (years) & $45(39-50)$ & $46(41-50)$ & 0.10 \\
\hline Intake of alcohol (g/week) & $104(20-181)$ & $76(16-171)$ & $<0.001$ \\
\hline Intake of red meat (servings/week) & $1.5(0.5-4.5)$ & $1.5(1.5-4.5)$ & $<0.001$ \\
\hline Intake of vegetables or green salad (servings/week) & $15.0(11.5-21.0)$ & $15.0(12.0-21.0)$ & 0.02 \\
\hline No (\%) using vitamin or mineral supplements & $1565(47.4)$ & $1987(44.0)$ & 0.003 \\
\hline No of deaths & 247 & 267 & - \\
\hline \multicolumn{4}{|l|}{ Relative risk $(95 \% \mathrm{Cl})$ : } \\
\hline Adjusted for age & 1.00 & $0.83(0.70-0.98)$ & 0.03 \\
\hline Adjusted for all variables in table & 1.00 & $0.73(0.60-0.89)$ & 0.002 \\
\hline
\end{tabular}

${ }^{*}$ Calculations may be based on fewer than 3312 candy non-consumers and 4529 candy consumers because of missing data. For continuous variables, tests for differences between medians used non-parametric

Wilcoxon rank sum tests since variables were not normally distributed. For categorical variables, differences in proportions were compared with $\chi^{2}$ tests.

†Estimated from walking, climbing stairs, and participating in sports or recreational activities.

Department of Epidemiology, Harvard School of Public Health, Boston, MA 02115, USA

I-Min Lee, assistant professor Ralph S

Paffenbarger Jr, adjunct professor certificates for men who died up to the end of 1993; mortality follow up was $>99 \%$ complete.

Table 1 compares the attributes of consumers and non-consumers of candy. We used Cox proportional hazards regression to estimate the relative risks of mortality associated with candy consumption. We initially adjusted for age and additionally accounted for other health habits (see table ) in multivariate models. Both cigarette habit and duration of smoking were included in multivariate models, with duration of 0 years assigned to men not smoking at baseline.

Consumers and non-consumers of candy differed in several ways. Those who did not indulge were older, leaner, and more likely to smoke (table). They drank more, ate less red meat and vegetables or green salad, and were more likely to take vitamin or mineral supplements. However, physical activity and duration of smoking among current smokers was similar in the two groups.

Between 1988 and 1993, 514 men died: 7.5\% of non-consumers, but only $5.9 \%$ of consumers (age adjusted relative risk $0.83 ; 95 \%$ confidence interval 0.70 to 0.98 ). Adjustment for other characteristics in the table strengthened the finding (relative risk 0.73; 0.60 to 0.89 ).

We then examined different levels of candy intake. Compared with non-consumers, the relative risks of mortality among men who consumed candy 1-3 times a month (1704 men), 1-2 times a week (1589 men), and 3 or more times a week (1236 men) were 0.64 (0.48 to 0.86 ), 0.73 (0.55 to 0.96), and 0.84 (0.64 to 1.11 ), respectively, in multivariate analysis $(\mathrm{P}$ for trend $=0.06$ ).

Finally, using life table analysis truncated at age 95, we estimated that (after adjustment for age and cigarette smoking) candy consumers enjoyed, on average, 0.92 (0.04 to 1.80) added years of life, up to age 95, compared with non-consumers.

\section{Comment}

Consumption of candy was associated with greater longevity in this study. Men who indulged lived almost a year longer, up to age 95 , than did abstainers.

We could not differentiate between consumption of sugar candy and chocolate in our study. One plausible explanation for our observations may be the presence of antioxidant phenols in chocolate. A $41 \mathrm{~g}$ piece of chocolate contains about the same amount of phenol as a glass of red wine, and alcohol consumption, in moderation, lowers the risk of coronary heart disease. ${ }^{3}$ Direct evidence regarding the antioxidant properties of chocolate also exists. Cacao liquor phenol can inhibit reactive oxygen species, as well as modulate immune function. ${ }^{4}$ Additionally, cacao powder extract is a powerful antioxidant for oxidation of low density lipoprotein cholesterol. ${ }^{5}$ These beneficial effects of chocolate may decrease the risk of heart disease and cancer.

Unfortunately, greater consumption of candy was not associated with progressively lower mortality. Mortality was lowest among those consuming candy 1-3 times a month and highest among those indulging this habit three or more times a week. Non-consumers of candy, however, still had the highest mortality overall. As with most things in life, moderation seems to be paramount.

This is report No LXXII in a series on chronic disease in former college students.

Funding: HL 34174 and CA 44854 from the National Institutes of Health.

Competing interests: The authors admit to a decided weakness for chocolate and confess to an average consumption of one bar a day each.

1 Krummel DA, Seligson FH, Guthrie HA. Hyperactivity: is candy causal? Crit Rev Food Sci Nutr 1996;36:31-47.

2 National Confectioners Association, Chocolate Manufacturers Association (USA). http://www.candyusa.org

3 Doll R. One for the heart. BMJ 1997;315:1664-8.

4 Sanbongi C, Suzuki N, Sakane T. Polyphenols in chocolate, which have antioxidant activity, modulate immune functions in humans in vitro. Cellular Immunol 1997;177:129-36.

5 Waterhouse AL, Shirley JB, Donovan JL. Antioxidants in chocolate. Lancet 1996;348:834.

\section{Favourite prayers The physician's prayer}

From inability to let well alone, from too much zeal for the new and contempt for what is old, from putting knowledge before wisdom, science before art and cleverness before common sense, from treating patients as cases and from making the cure of the disease more grievous than the endurance of the same, good Lord deliver us.

Sir Robert Hutchison (1871-1960).

From Favourite Prayers compiled by Deborah Cassidi; Cassell, 1998; ISBN 030470315 X, price $£ 9.99$. 